\title{
Impact of adherence to biological agents on health care resource utilization for patients over the age of 65 years with rheumatoid arthritis
}

This article was published in the following Dove Press journal:

Patient Preference and Adherence

6 July 2017

Number of times this article has been viewed

\author{
Urja Lathia \\ Emmanuel M Ewara \\ Francois Nantel \\ Janssen Inc., Toronto, ON, Canada
}

Correspondence: Francois Nantel Janssen Inc., 19 Green Belt Drive, Toronto, ON M3C IL9, Canada Email fnantel@its.jnj.com
Objective: Poor adherence to therapy increases the patient and societal burden and complexity of chronic diseases such as rheumatoid arthritis (RA). In the past 15 years, biologic diseasemodifying anti-rheumatic drugs (DMARDs) have revolutionized the treatment of RA. However, little data are available on the impact of adherence to biologics on health care resources. The objective of the study was to determine the long-term health care resource utilization patterns of RA patients who were adherent to biologic DMARD therapy compared to RA patients who were non-adherent to biologic DMARD therapy in an Ontario population and to determine factors influencing adherence.

Methods: Patients were identified from the Ontario RA Database that contains all RA patients in Ontario, Canada, identified since 1991. The study population included RA patients, aged $65+$ years, with a prescription for a biologic DMARD between 2003 and 2013. Exclusion criteria included diagnosis of inflammatory bowel disease, psoriatic arthritis or psoriasis in the 5 years prior to the index date and discontinuation of biologic DMARD, defined as no subsequent prescription during the 12 months after the index date. Adherence was defined as a medication possession ratio of $\geq 0.8$ measured as the proportion of days for which a patient had biologic treatment(s) over a defined follow-up period. Adherent patients were matched to non-adherent patients by propensity score matching.

Results: A total of 4,666 RA patients were identified, of whom 2,749 were deemed adherent and 1,917 non-adherent. The age (standard deviation) was 69.9 (5.46) years and $75 \%$ were female. Relative rates for resource use (physician visits, emergency visits, hospitalization, home care and rehabilitation) for the matched cohort were significantly lower $(P<0.0001)$ in adherent patients. Non-adherent patients' use of oral prednisone $(67 \%)$ was significantly higher $(P<0.001)$ than that of the adherent cohort $(56 \%)$.

Conclusion: RA patients adherent to biologic therapy have lower health care resource use and lower steroid use compared to non-adherent patients.

Keywords: anti-TNF, prednisone, DMARD, inflammation, administrative database

\section{Introduction}

Rheumatoid arthritis (RA) is a chronic autoimmune inflammatory disease characterized by persistent and progressive joint inflammation and destruction, resulting in pain, stiffness and functional disability. The primary presenting symptoms of RA include pain, weakness, stiffness, tenderness and swelling of the joints. The chronic inflammation leads to cartilage destruction, bone erosions and the formation of chronic granulation, scar tissue and bone fusions resulting in deformities of the hands, feet and other joints. Over time, and without appropriate treatment, this leads to loss of function and disability. 
Conventional treatment of RA with traditional diseasemodifying anti-rheumatic drugs (DMARDs) such as methotrexate (MTX) is recommended as first-line management of patients with persistent synovitis. ${ }^{1,2}$ During initial treatment with DMARD therapy, patients are often prescribed glucocorticoids or non-steroidal anti-inflammatory drugs (NSAIDs) as adjunctive therapy in addition to their DMARD(s) to help manage flares and symptoms if no other options are available. After failure with traditional DMARD therapy, treatment with a biologic DMARD is then often initiated. ${ }^{1,2}$

Adherence to prescribed drug therapies is necessary to prevent irreversible joint damage. ${ }^{3,4}$ However, studies indicate that adherence rate in RA patients varied between $49.5 \%$ and $98.5 \%$ depending on the definition and method used. ${ }^{4}$ Most of these studies evaluated DMARD therapy, and only a small number of them investigated adherence to anti-tumor necrosis factor (anti-TNF) therapies. ${ }^{5-7}$

The primary objective of this study was to determine the long-term health care resource utilization patterns of RA patients who were adherent to biologic DMARD therapy compared to RA patients who were non-adherent to biologic DMARD therapy in an Ontario population and to determine factors influencing adherence.

\section{Methods}

\section{Administrative databases}

This was a retrospective observational database study utilizing de-identified linked databases managed by the Institute for Clinical Evaluative Sciences (ICES). As part of a pilot project at the ICES, analyses were performed by ICES scientists on ICES administrative data to study the research question. The heath care resource outcomes measured included visits to general practitioner or family practitioner (GP/FP), rheumatologists, cardiologists and other medical doctors (MD), emergency department (ED) visits, hospitalizations and length of stay, same-day surgeries, home care services and rehabilitation services.

The following administrative databases were used in this study: The Continuing Care Reporting System - Long-Term Care (CCRS LTC), which contains demographic, clinical, functional and resource utilization information on individuals receiving continuing care services in long-term care homes; The Discharge Abstract Database (DAD), which contains patient-level data for acute, rehabilitation, chronic and day surgery institutions in Ontario; The Home Care Database (HCD), which captured all services provided by or coordinated by Ontario's Community Care Access Centers (CCACs); The National Ambulatory Care Reporting System (NACRS)/ Same Day Surgery (SDS), which captures information on patient visits to hospital and community-based ambulatory care: day surgery, outpatient clinics and EDs; The National Rehabilitation Reporting System (NRS), which contains client data collected from participating adult inpatient rehabilitation facilities and programs; The Ontario Drug Benefit (ODB), which contains claims for prescription drugs received under the ODB program; The Ontario Health Insurance Plan (OHIP), which contains most claims paid by the OHIP (the data cover all health care providers who can claim under OHIP - this includes physicians, groups, laboratories and out-of-province providers); The Postal Code Conversion File (PCCF), which links six-character postal codes to standard geographic areas such as dissemination areas, census tracts and census subdivisions; The Registered Persons Data Base files (RPDB), which provided basic demographic information about anyone who has ever received an Ontario health card number and finally, The Ontario Rheumatoid Arthritis Database (ORAD), which is an ICES-derived validated population-based cohort that contains all Ontario RA patients identified since 1991. In the ORAD database, incident cases were identified from 1995/1996. Cases were defined by having at least one inpatient Canadian Institute for Health Information (CIHI) DAD diagnosis code (any type) for RA (International Classification of Diseases [ICD]-9 714; ICD-10 M05, M06) or three physician OHIP claims with a diagnosis code for RA (ICD-9 714) over a 2-year period, with at least one claim by a musculoskeletal specialist (according to ICES Physician Database MAIN SPECIALTY: Rheumatology, Orthopedic surgery, or Internal medicine).

The administrative databases employed in the study rely on coded data. Personal identifiers are not provided to researchers. Therefore, patient privacy was not a concern in this study.

\section{Cohort definition}

The study included all subjects previously diagnosed with RA and aged 65 years and older from the ORAD database, with a prescription for a biologic DMARD between January 1, 2003, and December 31, 2013. The index date was the first prescription for a biologic DMARD (Table 1) between January 1, 2003, and December 31, 2013. The exclusions were a diagnosis of Crohn's disease, psoriatic arthritis, psoriasis or ulcerative colitis in the 5 years prior to the index date or the discontinuation of biologic drug defined as no subsequent prescription for any of the biologic drugs of interest during the 12 months after the index date.

\section{Variable definition}

Adherence was defined as the proportion of days for which a patient had biologic treatment(s) over their total overall 
Table I Biologic treatments of interest

\begin{tabular}{|c|c|c|c|}
\hline Brand name & Generic name & DIN & Dose and dose frequency \\
\hline \multicolumn{4}{|c|}{ Anti-TNF agents } \\
\hline \multirow[t]{4}{*}{ Humira } & Adalimumab & 02258595 & 40 mg every 2 weeks \\
\hline & & 09857294 & \\
\hline & & 09857326 & \\
\hline & & 09857327 & \\
\hline \multirow[t]{4}{*}{ Enbrel $^{\circledR}$} & Etanercept & 02242903 & $25 \mathrm{mg}$ twice weekly or $50 \mathrm{mg}$ once weekly \\
\hline & & 02274728 & \\
\hline & & 09857322 & \\
\hline & & 09857394 & \\
\hline \multirow[t]{2}{*}{ Remicade $^{\circledR}$} & Infliximab & 02244016 & $3 \mathrm{mg} / \mathrm{kg} /$ dose at 0 weeks, 2 weeks and 6 weeks followed by maintenance therapy of \\
\hline & & 09852956 & $3 \mathrm{mg} / \mathrm{kg} /$ dose every 8 weeks up to a maximum of six maintenance doses per year \\
\hline $\mathrm{Cimzia}^{\circledR}$ & Certolizumab & 02331675 & $\begin{array}{l}400 \mathrm{mg} \text { at } 0 \text { weeks, } 2 \text { weeks and } 4 \text { weeks followed by maintenance therapy of } 200 \mathrm{mg} \\
\text { every } 2 \text { weeks. For maintenance dosing, } 400 \mathrm{mg} \text { every } 4 \text { weeks may be considered }\end{array}$ \\
\hline \multirow[t]{2}{*}{ Simponi ${ }^{\circledast}$} & Golimumab & 02324776 & $50 \mathrm{mg}$ once a month \\
\hline & & 02324784 & \\
\hline \multicolumn{4}{|c|}{ Other mechanism of action } \\
\hline Kineret ${ }^{\circledR}$ & Anakinra & 02245913 & 100 mg per day \\
\hline \multirow[t]{3}{*}{ Actemra $^{\circledR}$} & Tocilizumab & 02350092 & $4 \mathrm{mg} / \mathrm{kg} /$ dose once every 4 weeks followed by an increase to $8 \mathrm{mg} / \mathrm{kg} /$ dose based \\
\hline & & 02350106 & on clinical response. For individuals whose body weight is $>100 \mathrm{~kg}$, doses exceeding \\
\hline & & 02350114 & $800 \mathrm{mg}$ per infusion are not recommended \\
\hline \multirow[t]{2}{*}{ Orencia $^{\circledast}$} & Abatacept & 02282097 & IV: Year I: $750 \mathrm{mg}$ at weeks 0,2 and 4 then every 4 weeks \\
\hline & & 02402475 & SC: $125 \mathrm{mg}$ weekly \\
\hline \multirow[t]{2}{*}{ Rituxan $^{\circledast}$} & Rituximab & 02241927 & One course of treatment is $1,000 \mathrm{mg}$ followed 2 weeks later by the second $1,000 \mathrm{mg}$ \\
\hline & & 09857407 & dose. Two courses will be approved each year (courses should be at least 6 months) \\
\hline
\end{tabular}

Abbreviations: DIN, drug identification number; TNF, tumor necrosis factor; IV, intravenously; SC, subcutaneously.

follow-up period (Table 1 for the list of biologics included). Adherence was determined using the medication possession ratio (MPR): MPR $=$ (Days supplied for the drug of interest $/$ Follow-up time). Patients were considered adherent if they had an MPR of 0.8 or higher, a commonly used measure in studies on adherence. ${ }^{3,4,8}$ Days' supply was captured in the ODB database. Additional variables reported at baseline or at index date were the year of index date, age, sex, income status, rural status and the resource utilization band (RUB). Further, heath care resource utilization in the year prior to the index date was reported, which included: GP/ FP, rheumatologists, cardiologists and other MD visits, ED visits, hospitalizations and length of stay, same-day surgeries, home care services and rehabilitation services. In order to further characterize the study cohort, prior use (1 year prior to index date) of NSAIDs/COX-2 inhibitors (COX-2), corticosteroids, DMARDs and anti-hypertensives was also reported.

\section{Statistical analyses}

Multivariate logistic regression was used to identify factors that influence adherence. The equation is in the format:

$$
\begin{aligned}
\text { Adherence }(1 / 0)= & b_{0}+b_{1}(\text { age })+b_{2}(\text { sex }) \\
& +b_{3}(\text { income quintile } 1)+\ldots b_{n} X_{n}
\end{aligned}
$$

where patient adherence was the dependent variable and baseline characteristics at index and previous resource use in the year prior to index date were the independent variables. The multivariate logistic regression analysis was used to determine the adjusted odds ratios (ORs) for each variable, adjusted for all other patient characteristics. For example, $\log (\mathrm{b} 1)$ would capture the impact of age on determining adherence, adjusting for sex, income quintile and other variables. The variables evaluated in the model included age at index date, sex, income status at index date, rural status at index date, long-term care resident status at index date and the RUB at index date. Further, health care resource utilization in 1 year prior to the index date was included in the model as well, which included GP/FP, rheumatologists, cardiologists and other MD visits, ED visits, hospitalizations and length of stay, same-day surgeries, home care services and rehabilitation services.

To capture differences in the health care resource use of adherent and non-adherent patients, adherent and nonadherent patients were matched on a propensity score (PS) calculated using baseline characteristics including age, sex, income quintile, Local Health Integration Network of residence, rurality, long-term care residence, RUB status, index year of first biologic script and health services use 1 year prior to index date (visits to GP/FP, rheumatologists, 
cardiologists and other MDs, ED visits, hospitalizations, same-day surgeries, home care services and rehabilitation episodes). The PS model included all the 17 variables that were available in the data set since there were differences observed in variables between the adherent and the non-adherent cohort at baseline (Table 2). Specifically, it was important to balance the cohorts based on index year since the proportion of adherent to non-adherent patients varied depending on the index year. Further, the inclusion of all available variables would ensure that all potential confounders were corrected for. Once patients were matched, the unadjusted rate of each health care resource per person per 100 days was captured over each patient's total follow-up time. The relative rates capturing the differences in the rate of each health care resource use was then modeled assuming that outcomes followed a negative binomial distribution.

As a sensitivity analysis, three separate matched cohorts capturing patients with 3 years, 5 years and 7 years of follow-up were developed (1,095 days, 1,825 days and
2,555 days of follow-up, respectively, from the date of the first claim for any of the biologic treatments of interest) and reported the mean and median health care resource utilization per 100 days for adherent and non-adherent patients.

\section{Results}

A total of 4,666 RA patients were identified, of whom 2,749 (59\%) were deemed adherent and 1,917 (41\%) non-adherent. The age (standard deviation [SD]) was 69.9 (5.46) years and 75\% were female (Table 2). There were a greater proportion of non-adherent patients from 2003 to 2010, while a larger number of adherent patients were identified from 2011 onward. Adherent patients tended to be significantly younger and from a higher income quintile than non-adherent patients. In the year prior to the index date, there were a lower number of adherent patients in the higher RUB $(P<0.001$; Table 2). Indeed, adherent patients had a slightly lower number of GP visits (mean [SD] of 12.1 [12.5] vs 13.5 [12.6]; $P<0.001$ ), ED visits (mean [SD] of

Table 2 Baseline characteristics

\begin{tabular}{|c|c|c|c|c|}
\hline \multirow[t]{2}{*}{ Characteristics } & \multirow{2}{*}{$\frac{\text { Overall }}{N=4,667}$} & \multirow{2}{*}{$\begin{array}{l}\text { Adherent }(M P R \geq 0.8) \\
n=2,196\end{array}$} & \multirow{2}{*}{$\frac{\text { Non-adherent }(M P R<0.8)}{n=2,47 \text { I }}$} & \multirow[t]{2}{*}{$P$-value } \\
\hline & & & & \\
\hline Index year, n (\%) & & & & $<0.001$ \\
\hline 2003 & $456(9.8)$ & 149 (6.8) & $307(12.4)$ & \\
\hline 2004 & $237(5.1)$ & $78(3.6)$ & $159(6.4)$ & \\
\hline 2005 & $283(6.1)$ & $97(4.4)$ & $186(7.5)$ & \\
\hline 2006 & $279(6)$ & $97(4.4)$ & $182(7.4)$ & \\
\hline 2007 & $327(7)$ & $135(6.1)$ & $192(7.8)$ & \\
\hline 2008 & $406(8.7)$ & $166(7.6)$ & $240(9.7)$ & \\
\hline 2009 & $451(9.7)$ & $200(9.1)$ & $251(10.2)$ & \\
\hline 2010 & $349(7.5)$ & $157(7.1)$ & $192(7.8)$ & \\
\hline 2011 & $524(11.2)$ & $291(13.3)$ & $233(9.4)$ & \\
\hline 2012 & $658(14.1)$ & $385(17.5)$ & $273(11)$ & \\
\hline Long-term care resident, n (\%) & $27(0.6)$ & $13(0.7)$ & $14(0.5)$ & 0.454 \\
\hline \multicolumn{5}{|l|}{ Demographics } \\
\hline Age, mean (SD) & $69.94(5.46)$ & $70.60(5.69)$ & $69.47(5.24)$ & $<0.001$ \\
\hline Female, $\mathrm{n}(\%)$ & $3,500(75.0)$ & I,453 (75.8) & $2,047(74.5)$ & 0.301 \\
\hline Income quintile, $n(\%)$ & & & & 0.211 \\
\hline Missing & $16(0.3)$ & $8(0.4)$ & $8(0.3)$ & \\
\hline I- lowest & $744(15.9)$ & $323(16.8)$ & $421(15.3)$ & \\
\hline 2 & $892(19.1)$ & $385(20.1)$ & $507(18.4)$ & \\
\hline 3 & $946(20.3)$ & $386(20.1)$ & $560(20.4)$ & \\
\hline 4 & $1,055(22.6)$ & $405(2 I .1)$ & $650(23.6)$ & \\
\hline 5 - highest & $1,013(21.7)$ & $410(21.4)$ & $603(21.9)$ & \\
\hline \multicolumn{5}{|l|}{ Geographics } \\
\hline Rural, n (\%) & $706(15.1)$ & $354(16.1)$ & $352(14.2)$ & 0.074 \\
\hline \multicolumn{5}{|l|}{ Health resource utilization } \\
\hline RUB, n (\%) & & & & $<0.001$ \\
\hline $0-2$ & $\mathrm{II}(0.2)$ & $6-10^{*}$ & $1-5 *$ & \\
\hline 3 & $2,296(49.2)$ & $864(45.1)$ & I,432 (52.I) & \\
\hline 4 & $1,580(33.9)$ & $687(35.8)$ & $893(32.5)$ & \\
\hline 5 & $779(16.7)$ & $356-360 *$ & $419-423^{*}$ & \\
\hline
\end{tabular}


Table 2 (Continued)

\begin{tabular}{|c|c|c|c|c|}
\hline \multirow[t]{2}{*}{ Characteristics } & \multirow{2}{*}{$\frac{\text { Overall }}{\mathrm{N}=4,667}$} & \multirow{2}{*}{$\begin{array}{l}\text { Adherent }(M P R \geq 0.8) \\
\mathrm{n}=2,196\end{array}$} & \multirow{2}{*}{$\frac{\text { Non-adherent }(M P R<0.8)}{n=2,47 I}$} & \multirow[t]{2}{*}{$P$-value } \\
\hline & & & & \\
\hline \multicolumn{5}{|l|}{ MD visits } \\
\hline \multicolumn{5}{|l|}{ GP/FP } \\
\hline Any visit, n (\%) & $4,562(97.8)$ & I,873 (97.7) & 2,689 (97.8) & 0.798 \\
\hline Mean (SD) & $12.7(12.57)$ & I3.5 (I2.57) & $12.1(12.54)$ & $<0.001$ \\
\hline Median (IQR) & $9(5-16)$ & $10(6-17)$ & $9(5-15)$ & $<0.001$ \\
\hline \multicolumn{5}{|l|}{ Rheumatologist } \\
\hline Any visit, n (\%) & $2,682(57.5)$ & $\mathrm{I}, 045(54.5)$ & I,637 (59.5) & $<0.001$ \\
\hline Mean (SD) & $3.7(4.89)$ & $3.5(4.89)$ & $3.9(4.89)$ & 0.017 \\
\hline Median (IQR) & $2(0-6)$ & $\mathrm{I}(0-6)$ & $2(0-6)$ & 0.017 \\
\hline \multicolumn{5}{|l|}{ Cardiologist } \\
\hline Any visit, n (\%) & I, I 44 (24.5) & $512(26.7)$ & $632(23)$ & 0.004 \\
\hline Mean (SD) & $0.6(1.99)$ & $0.7(2.44)$ & $0.5(1.6)$ & 0.001 \\
\hline Median (IQR) & $0(0-0)$ & $0(0-1)$ & $0(0-0)$ & 0.001 \\
\hline \multicolumn{5}{|l|}{ Other } \\
\hline Any visit, n (\%) & 4,589 (98.3) & I,89| (98.6) & $2,698(98.1)$ & 0.188 \\
\hline Mean (SD) & $12.8(10.25)$ & I3.5 (| I.52) & $12.3(9.22)$ & $<0.001$ \\
\hline Median (IQR) & $11(6-17)$ & $11(6-18)$ & $10(6-17)$ & $<0.001$ \\
\hline \multicolumn{5}{|l|}{ ED visits } \\
\hline Any visit, n (\%) & I,706 (36.6) & 777 (40.5) & $929(33.8)$ & $<0.001$ \\
\hline Mean (SD) & $0.7(\mathrm{I} .42)$ & $0.9(1.6)$ & $0.7(1.27)$ & $<0.001$ \\
\hline Median (IQR) & $0(0-I)$ & $0(0-1)$ & $0(0-I)$ & $<0.001$ \\
\hline \multicolumn{5}{|l|}{ Same-day surgeries } \\
\hline Any visit, n (\%) & I, I $80(25.3)$ & $502(26.2)$ & $678(24.7)$ & 0.239 \\
\hline Mean (SD) & $0.4(0.76)$ & $0.4(0.77)$ & $0.4(0.75)$ & 0.521 \\
\hline Median (IQR) & $0(0-1)$ & $0(0-1)$ & $0(0-0)$ & 0.521 \\
\hline \multicolumn{5}{|l|}{ Hospitalizations } \\
\hline Any visit, n (\%) & $845(18.1)$ & $410(21.4)$ & $435(15.8)$ & $<0.001$ \\
\hline Mean (SD) & $0.2(0.59)$ & $0.3(0.64)$ & $0.2(0.55)$ & $<0.001$ \\
\hline Median (IQR) & $0(0-0)$ & $0(0-0)$ & $0(0-0)$ & $<0.001$ \\
\hline \multicolumn{5}{|l|}{ LOS } \\
\hline Mean (SD) & $9.1(12.18)$ & $9.1(11.6)$ & $9.1(12.72)$ & 0.96 \\
\hline Median (IQR) & $5(3-10)$ & $6(3-10)$ & $5(2-10)$ & 0.96 \\
\hline \multicolumn{5}{|l|}{ Home care } \\
\hline Any service, n (\%) & $338(7.2)$ & $170(8.9)$ & $168(6.1)$ & $<0.001$ \\
\hline Mean (SD) & $7.7(47.32)$ & $10.3(57.08)$ & $5.8(39.01)$ & 0.001 \\
\hline Median (IQR) & $0(0-0)$ & $0(0-0)$ & $0(0-0)$ & 0.001 \\
\hline \multicolumn{5}{|l|}{ Rehabilitation } \\
\hline Any rehabilitation, n (\%) & $48 I(10.3)$ & $206(10.7)$ & $275(10)$ & 0.412 \\
\hline Mean $(S D)$ & $0.1(0.47)$ & $0.1(0.49)$ & $0.1(0.45)$ & 0.351 \\
\hline Median (IQR) & $0(0-0)$ & $0(0-0)$ & $0(0-0)$ & 0.351 \\
\hline
\end{tabular}

Note: *Suppressed for privacy.

Abbreviations: MPR, medication possession ratio; SD, standard deviation; RUB, resource utilization band; MD, medical doctor; GP, general practitioner; FP, family practitioner; IQR, interquartile range; ED, emergency department; LOS, length of stay.

0.7 [1.3] vs 0.9 [1.6]; $P<0.001$ ), hospitalizations (mean [SD] of 0.2 [0.5] vs $0.3[0.6] ; P<0.001)$ and home care visits (mean [SD] of 5.8 [39.0] vs 10.3 [57.1]; $P=0.001$ ). In contrast, non-adherent patients had a lower number of rheumatologists visits (mean [SD] of 3.5 [5.0] vs 3.9 [4.9]; $P<0.017)$.

Multivariate logistic regression was used to identify factors that predict the overall adherence to biologic drugs (Table 3). Increased age (OR 0.96 [0.95-0.97]; $P<0.0001$ ), previous use of NSAIDs/COXIBs (OR 0.84 [0.75-0.94];
$P=0.0035$ ), use of oral prednisone (OR 0.76 [0.67-0.85]; $P<0.0001$ ) and use of anti-hypertensives (OR 0.74 [0.66-0.83]; $P<0.0001)$ were significantly associated with non-adherence. In contrast, being in a higher income quintile of 4 (OR 1.23 [1.02-1.49]; $P=0.033$ ), living in south east Ontario (OR 1.72 [1.19-2.50]; $P=0.004$ ) and visits to the rheumatologist (OR 1.02 [1.00-1.03]; $P<0.0078$ ) were associated with adherence.

The impact of adherence on concomitant medication use is presented in Table 4. Since ODB only covers patients 
Table 3 Logistic regression results predicting overall adherence to biologic drugs among patients with RA in Ontario

\begin{tabular}{|c|c|}
\hline & Odds ratio $(95 \% \mathrm{CI})$ \\
\hline \multicolumn{2}{|l|}{ Patient characteristics } \\
\hline Age & $0.97(0.96-0.98)$ \\
\hline Female & $0.93(0.81-1.07)$ \\
\hline \multicolumn{2}{|l|}{ Income quintile (REF =I - lowest) } \\
\hline 2 & $1.03(0.84-1.26)$ \\
\hline 3 & $1.12(0.91-1.36)$ \\
\hline 4 & $1.22(1.0-1.49)$ \\
\hline 5 - highest & I.I 4 (0.94-I.39) \\
\hline Rural & I.I8 (0.98-1.43) \\
\hline Long-term care resident & $1.23(0.55-2.75)$ \\
\hline \multicolumn{2}{|l|}{ Drug use prior to index date } \\
\hline NSAIDs/COXIBs & $0.83(0.73-0.94)$ \\
\hline \multicolumn{2}{|l|}{ Corticosteroids } \\
\hline Oral prednisone & $0.89(0.78-1.01)$ \\
\hline Intra-articular steroid injections & $0.96(0.84-1.10)$ \\
\hline Other & $0.48(0.19-1.25)$ \\
\hline \multicolumn{2}{|l|}{ DMARDs } \\
\hline MTX & $1.19(1.05-1.36)$ \\
\hline Others & $1.16(1.01-1.33)$ \\
\hline Anti-hypertensives & $0.84(0.79-0.96)$ \\
\hline \multicolumn{2}{|l|}{ Health services use prior to index date } \\
\hline \multicolumn{2}{|l|}{ RUB (REF $=0-2)$} \\
\hline 3 & $2.8 \mathrm{I}(0.8-9.85)$ \\
\hline 4 & $2.42(0.69-8.53)$ \\
\hline 5 & $2.63(0.74-9.36)$ \\
\hline \multicolumn{2}{|l|}{ Number of MD visits } \\
\hline GP/FP & $1.00(0.99-1.00)$ \\
\hline Rheumatologist & $1.02(1.00-1.03)$ \\
\hline Cardiologist & $0.97(0.94-1.01)$ \\
\hline Others & $1.00(0.99-1.00)$ \\
\hline Number of ED visits & $0.96(0.91-1.01)$ \\
\hline Number of same-day surgeries & $1.04(0.96-1.13)$ \\
\hline Number of hospitalizations & $0.95(0.83-1.08)$ \\
\hline Number of home care services & $1.00(1.00-1.00)$ \\
\hline Number of rehabilitation services & $1.05(0.9 \mid-1.20)$ \\
\hline
\end{tabular}

Note: Bold represent statistically significant values.

Abbreviations: RA, rheumatoid arthritis; REF, reference; NSAIDs, non-steroidal anti-inflammatory drugs; COXIBs, COX-2 inhibitors; DMARDs, disease-modifying anti-rheumatic drugs; MTX, methotrexate; RUB, resource utilization band; MD, medical doctor; GP, general practitioner; FP, family practitioner; ED, emergency department.

65 years and older, the cohorts only included patients aged 66 years and older at the index date to allow the evaluation of drug use prior to the index date. In this cohort of 3,181 patients, $1,418(45 \%)$ were labeled as non-adherent and $1,763(55 \%)$ were labeled as adherent. Prior to the index date, a lower proportion of adherent patients were taking oral prednisone $(52.4 \%$ vs $56.1 \%, P=0.033)$ and anti-hypertensives $(61.5 \%$ vs $65.8 \%, P=0.012)$. In contrast, adherent patients were more likely to be taking MTX $(66.8 \%$ vs $59.7 \%, P<0.001)$ or other DMARDs $(79.4 \%$ vs $73.5 \%$, $P<0.001)$. After the index date, when patients were taking biologic therapy, adherent patients were less likely to be taking concomitant NSAIDs/COXIBs $(53.5 \%$ vs $58.5 \%$, $P=0.006)$, corticosteroids $(72.3 \%$ vs $79 \%, P<0.001)$ including oral prednisone $(56.3 \%$ vs $67.3 \%, P<0.001)$ and intra-articular steroid injections ( $51.3 \%$ vs $55.4 \%, P=0.024$ ) and anti-hypertensives ( $74.8 \%$ vs $80.7 \%, P<0.001)$. Concomitant non-biologic DMARD use was similar between the two groups.

Finally, to evaluate health care resource utilization and to limit potential biases, adherent patients and nonadherent patients were matched on a PS calculated using 17 confounding variables. All available variables were utilized in the calculation of the PS since the adherent and non-adherent patient cohorts differed with respect to year of index date, age, income quintile and health care resource use in the year prior to index date. Further, it would be particularly important to match the cohorts on the prior health care resource use as this would ensure that any divergence observed in the follow-up period in health care resource use was an impact of adherence to medication.

The matched cohort included a total 3,686 patients, 1,843 per group (Table 5). In contrast to the whole cohort, there was no significant difference in follow-up time between the two matched groups. The relative rate of visits to GPs, cardiologists and other physicians were, respectively, 13\%, $22 \%$ and $18 \%$ lower in adherent patients. Interestingly, the mean number of visits to a rheumatologist was $6 \%$ higher in adherent patients. Also, the relative rate of hospitalization, ED visits, same-day surgeries and home care visits were 32\%, $25 \%, 9 \%$ and $28 \%$ lower, respectively, in adherent patients. Moreover, the median length of stay was shorter by 8 days, in adherent patients. Overall, the relative rates for all health care resource use end points were significantly lower in adherent patients except for rheumatologist visits (Table 6).

\section{Discussion}

The results of this study clearly show that, in a population cohort of RA patients, adherence to biologic DMARD therapy might be associated with lower health care resource utilization and clearly demonstrates the benefit of adherence to therapy when treating chronic inflammatory diseases such as RA.

There was a larger proportion of non-adherent patients in earlier index years (2003-2010) over later index years that could be explained either by better education on adherence or, more likely, by a longer duration of follow-up in the use of the MPR, which can be associated with a greater chance of being qualified as non-adherent. Additional differences at baseline were noted between adherent and non-adherent 
Table 4 Medication use, among those aged 66 years and older, before and after the index date

\begin{tabular}{|c|c|c|c|c|}
\hline \multirow[t]{2}{*}{ Drug group, n (\%) } & \multirow{2}{*}{$\frac{\text { Overall }}{\mathrm{N}=3,181}$} & \multirow{2}{*}{$\begin{array}{l}\text { Adherent }(M P R \geq 0.8) \\
n=1,418\end{array}$} & \multirow{2}{*}{$\begin{array}{l}\text { Non-Adherent }(M P R<0.8) \\
n=1,763\end{array}$} & \multirow[t]{2}{*}{$P$-value } \\
\hline & & & & \\
\hline \multicolumn{5}{|l|}{ Prior to index date } \\
\hline NSAIDs/COXIBs & $\mathrm{I}, 607(50.5)$ & $724(5 \mathrm{I} .1)$ & $883(50.1)$ & 0.585 \\
\hline \multicolumn{5}{|l|}{ Corticosteroids } \\
\hline Any use & $2,136(67.1)$ & $960(67.7)$ & $1,176(66.7)$ & 0.552 \\
\hline Oral prednisone & $1,719(54)$ & $796(56.1)$ & $923(52.4)$ & 0.033 \\
\hline Intra-articular steroid injections & $\mathrm{I}, 433(45)$ & $623(43.9)$ & $810(45.9)$ & 0.258 \\
\hline Others & $16(0.5)$ & $11-15$ & $\mathrm{I}-5$ & 0.051 \\
\hline \multicolumn{5}{|l|}{ DMARDs } \\
\hline Any use & $2,869(90.2)$ & $1,258(88.7)$ & $1,611(91.4)$ & 0.012 \\
\hline MTX & $2,024(63.6)$ & $846(59.7)$ & $1,178(66.8)$ & $<0.001$ \\
\hline Others & $2,442(76.8)$ & $1,042(73.5)$ & $1,400(79.4)$ & $<0.001$ \\
\hline Anti-hypertensives & $2,017(63.4)$ & $933(65.8)$ & $1,084(6 I .5)$ & 0.012 \\
\hline \multicolumn{5}{|l|}{ Index date to the end of follow-up } \\
\hline NSAIDs/COXIBs & $\mathrm{I}, 773(55.7)$ & $829(58.5)$ & $944(53.5)$ & 0.006 \\
\hline \multicolumn{5}{|l|}{ Corticosteroids } \\
\hline Any use & $2,394(75.3)$ & I, I 20 (79) & $1,274(72.3)$ & $<\mathbf{0 . 0 0 1}$ \\
\hline Oral prednisone & $1,947(61.2)$ & $955(67.3)$ & $992(56.3)$ & $<0.001$ \\
\hline Intra-articular steroid injections & $1,690(53.1)$ & $785(55.4)$ & $905(5 I .3)$ & 0.024 \\
\hline Others & $109(3.4)$ & $65(4.6)$ & $44(2.5)$ & 0.001 \\
\hline \multicolumn{5}{|l|}{ DMARDs } \\
\hline Any use & $2,656(83.5)$ & $\mathrm{I}, \mathrm{I} 74(82.8)$ & $\mathrm{I}, 482(84 . \mathrm{I})$ & 0.338 \\
\hline MTX & $1,913(60.1)$ & $832(58.7)$ & $1,081(61.3)$ & 0.13 \\
\hline Others & $1,693(53.2)$ & 797 (56.2) & $896(50.8)$ & 0.002 \\
\hline Anti-hypertensives & $2,463(77.4)$ & $1,145(80.7)$ & $1,318(74.8)$ & $<0.001$ \\
\hline
\end{tabular}

Note: Bold represent statistically significant values.

Abbreviations: MPR, medication possession ratio; NSAIDs, non-steroidal anti-inflammatory drugs; COXIBs, COX-2 inhibitors; DMARDs, disease-modifying anti-rheumatic drugs; MTX, methotrexate.

patients, most notably in age and income quintile that, although statistically significant, were very small numerically and are unlikely to be clinically relevant. Small numerical, yet statistically significant differences in health resource use were noted prior to the index date. Although the effect size is much smaller than what we observed after the index date in a matched cohort of patients, the similar pattern could reflect non-adherence to conventional therapy, although that was not examined in this study.

This study identified a number of factors associated with adherence including increased age. ${ }^{6,7,9} \mathrm{With}$ respect to medications, another study has reported a strong positive association between a prescription for DMARDs 6 months prior to anti-TNF treatment and adherence. ${ }^{5}$ We did not find that association although it is likely caused by the reimbursement criteria for biologic DMARD therapy in Ontario that requires prior failure of one to three DMARDs, and that $90.2 \%$ of the cohort was already on DMARDs. However, we did identify an association between use of NSAIDs/ COXIBs and oral prednisone and non-adherence. A possible explanation is that these patients have more active disease (which could be due to non-adherence) or that the higher number of concomitant medications increases the risk for non-adherence. Living in a rural environment and more frequent visits to a rheumatologist were also associated with better adherence.

Being adherent to biologic DMARD therapy was associated with a significant reduction in all health care resource utilization outcomes measured, except for visits to a rheumatologist, which was slightly greater in adherent patients. A previous study investigating adherence to anti-TNF therapy also found that adherent patients had $21.5 \%$ reduction in mean annual non-pharmacological expenditure for each patient, ${ }^{7}$ a rate almost identical to what we found in this study.

There was a significantly higher proportion of nonadherent RA patients who were using NSAIDs/COXIBs and corticosteroids such as oral prednisone and intra-articular steroid injections. This difference was noted in the pre-index date but increased by over two-fold once those patients were under biologic DMARD therapy, while no change was noted in the use of DMARDs and anti-hypertensives. It is possible that non-adherence to biologic DMARDs lead to a greater incidence of disease flare, which is then managed with NSAIDs/COXIBs and corticosteroids. ${ }^{1}$

Although utilizing health administrative databases has many benefits, a limitation is that data are collected for 
Table 5 Resource use for the matched* cohort

\begin{tabular}{|c|c|c|c|c|}
\hline \multirow[t]{3}{*}{ Resource } & \multicolumn{3}{|l|}{ Resource use } & \multirow[t]{3}{*}{$P$-value } \\
\hline & \multirow{2}{*}{$\begin{array}{l}\text { Total } \\
\mathrm{N}=3,686 \\
\end{array}$} & \multirow{2}{*}{$\begin{array}{l}\text { Adherent }(M P R \geq 0.8) \\
n=I, 843\end{array}$} & \multirow{2}{*}{$\begin{array}{l}\text { Non-adherent }(M P R<0.8) \\
n=l, 843\end{array}$} & \\
\hline & & & & \\
\hline \multicolumn{5}{|l|}{ Follow-up time (days) } \\
\hline Mean (SD) & $\mathrm{I}, 943(\mathrm{I}, \mathrm{II})$ & I,919 (I,085) & $1,967(I, 138)$ & 0.187 \\
\hline Median (IQR) & $\mathrm{I}, 83 \mathrm{I}(\mathrm{I}, 003-2,736)$ & I,828 (974-2,673) & $\mathrm{I}, 836(\mathrm{I}, 0 \mid \mathrm{I}-2,786)$ & 0.187 \\
\hline \multicolumn{5}{|l|}{ GP/FP } \\
\hline Any visit, n (\%) & $3,670(99.6)$ & $\mathrm{I}, 834(99.5)$ & $\mathrm{I}, 836(99.6)$ & 0.616 \\
\hline \multicolumn{5}{|c|}{ Rate per 100 follow-up days } \\
\hline Mean (SD) & $4.34(3.80315)$ & $4.7(4.06444)$ & $3.97(3.4845 \mathrm{I})$ & $<0.001$ \\
\hline Median (IQR) & $3.25(1.9753-5.3486)$ & $3.58(2.1277-5.8315)$ & $2.93(1.8328-4.798)$ & $<0.001$ \\
\hline \multicolumn{5}{|l|}{ Rheumatologist } \\
\hline Any visit, n (\%) & $3,161(85.8)$ & $\mathrm{I}, 562(84.8)$ & $1,599(86.8)$ & $0.08 \mathrm{I}$ \\
\hline \multicolumn{5}{|c|}{ Rate per 100 follow-up days } \\
\hline Mean (SD) & $\mathrm{I} .37(\mathrm{I} .44)$ & $1.25(1.38)$ & 1.49 (I.49) & $<0.001$ \\
\hline Median (IQR) & $0.96(0.34-1.93)$ & $0.84(0.26-1.75)$ & $1.09(0.46-2.08)$ & $<0.001$ \\
\hline \multicolumn{5}{|l|}{ Cardiologist } \\
\hline Any visit, n (\%) & $2,588(70.2)$ & I,352 (73.4) & $\mathrm{I}, 236(67.1)$ & $<0.001$ \\
\hline \multicolumn{5}{|c|}{ Rate per 100 follow-up days } \\
\hline Mean (SD) & $0.34(0.68)$ & $0.39(0.75)$ & $0.29(0.59)$ & $<0.001$ \\
\hline Median (IQR) & $0.12(0-0.37)$ & $0.15(0-0.44)$ & $0.097(0-0.31)$ & $<0.001$ \\
\hline \multicolumn{5}{|l|}{ Other } \\
\hline Any visit, n (\%) & $3,682(99.9)$ & I,84I (99.9) & I,84I (99.9) & 1 \\
\hline \multicolumn{5}{|c|}{ Rate per 100 follow-up days } \\
\hline Mean (SD) & $4.59(3.88)$ & $5.00(4.31)$ & $4.2(3.35)$ & $<0.001$ \\
\hline Median (IQR) & $3.7(2.27-5.6)$ & $3.9(2.38-6.17)$ & $3.47(2.13-5.26)$ & $<0.001$ \\
\hline \multicolumn{5}{|l|}{ ED visits } \\
\hline Any visit, n (\%) & $3,059(83)$ & $\mathrm{I}, 60 \mathrm{I}(86.9)$ & I,458 (79.1) & $<0.001$ \\
\hline \multicolumn{5}{|c|}{ Rate per 365 follow-up days } \\
\hline Mean (SD) & I.7I (I.75) & $1.35(2.00)$ & $1.00(1.50)$ & $<0.001$ \\
\hline Median (IQR) & $0.69(0.23-\mid .5 I)$ & $0.84(0.33-1.64)$ & $0.55(0.16-1.20)$ & $<0.001$ \\
\hline \multicolumn{5}{|l|}{ Same-day surgeries } \\
\hline Any visit, n (\%) & $2,386(64.7)$ & $\mathrm{I}, 2 \mathrm{I} 4(65.9)$ & I, I $72(63.6)$ & 0.148 \\
\hline \multicolumn{5}{|c|}{ Rate per 365 follow-up days } \\
\hline Mean (SD) & $0.37(0.58)$ & $0.39(0.58)$ & $0.35(0.57)$ & 0.037 \\
\hline Median (IQR) & $0.23(0-0.52)$ & $0.25(0-0.54)$ & $0.22(0-0.50)$ & 0.037 \\
\hline \multicolumn{5}{|l|}{ Hospitalizations } \\
\hline Any visit, n (\%) & $2,390(64.8)$ & $\mathrm{I}, 293(70.2)$ & $\mathrm{I}, 097(59.5)$ & $<0.001$ \\
\hline Rate per 365 follow-up d & & & & \\
\hline Mean (SD) & $0.48(0.78)$ & $0.58(0.80)$ & $0.39(0.75)$ & $<0.001$ \\
\hline Median (IQR) & $0.24(0-0.62)$ & $0.33(0-0.78)$ & $0.18(0-0.48)$ & $<0.001$ \\
\hline Length of stay (in days) & & & & \\
\hline Mean (SD) & $29.93(40.5)$ & $37.69(48.62)$ & $20.79(25.18)$ & $<0.001$ \\
\hline Median (IQR) & $15(6-38)$ & $19(6-51)$ & II (5-28) & $<0.001$ \\
\hline Home care & & & & \\
\hline Any service, $\mathrm{n}(\%)$ & $\mathrm{I}, 220(33.1)$ & $723(39.2)$ & $497(27)$ & $<0.001$ \\
\hline Rate per 365 follow-up & & & & \\
\hline Mean (SD) & $23.86(75.92)$ & $28.10(76.76)$ & $19.60(75.19)$ & $<0.001$ \\
\hline Median (IQR) & $0(0-1.2195)$ & $0(0-3.2164)$ & $0(0-0.1628)$ & $<0.001$ \\
\hline Rehabilitation & & & & \\
\hline Any rehabilitation, n (\%) & $533(14.5)$ & $327(17.7)$ & $206(11.2)$ & $<0.001$ \\
\hline Rate per 365 follow-up & & & & \\
\hline Mean (SD) & $0.04(0.135)$ & $0.05(0.16)$ & $0.02(0.01)$ & $<0.001$ \\
\hline Median (IQR) & $0(0-0)$ & $0(0-0)$ & $0(0-0)$ & $<0.001$ \\
\hline
\end{tabular}

Notes: *Adherent patients were matched to non-adherent patients on a PS calculated using age, sex, income quintile, LHIN of residence, rurality, RUB, index year of first biologic script and health services use prior to index date (visits to GP/FP, rheumatologists, cardiologists and other MDs, ED visits, hospitalizations, same-day surgeries, home care services and rehabilitation episodes).

Abbreviations: MPR, medication possession ratio; SD, standard deviation; IQR, interquartile range; GP, general practitioner; FP, family practitioner; ED, emergency department; PS, propensity score; RUB, resource utilization band; MD, medical doctor; LHIN, Local Health Integration Network. 
Table 6 Relative rates for resource use for the matched* cohort, using negative binomial distribution

\begin{tabular}{llll}
\hline Resource use & \multicolumn{3}{l}{ Adherence over entire follow-up period } \\
\cline { 2 - 4 } & Relative rate & Lower CL & Upper CL \\
\hline MD visits & & & \\
GP/FP & 0.88 & 0.83 & 0.93 \\
Rheumatologist & 1.06 & 1.00 & 1.12 \\
Cardiologist & 0.78 & 0.69 & 0.88 \\
$\quad$ Others & 0.82 & 0.78 & 0.86 \\
ED visits & 0.75 & 0.69 & 0.82 \\
Same-day surgeries & 0.91 & 0.84 & 0.98 \\
Hospitalizations & 0.68 & 0.63 & 0.74 \\
Home care & 0.72 & 0.55 & 0.93 \\
Rehabilitation & 0.60 & 0.49 & 0.74 \\
\hline
\end{tabular}

Notes: *Adherent patients were matched to non-adherent patients on a PS calculated using age, sex, income quintile, LHIN of residence, rurality, RUB, index year of first biologic script and health services use prior to index date (visits to GP/FP, rheumatologists, cardiologists, and other MDs, ED visits, hospitalizations, same-day surgeries, home care services and rehabilitation episodes).

Abbreviations: $\mathrm{CL}$, confidence limit; $\mathrm{MD}$, medical doctor; GP, general practitioner; FP, family practitioner; ED, emergency department; PS, propensity score; RUB, resource utilization band; LHIN, Local Health Integration Network.

administrative or billing purposes and are therefore subject to limitations. Health administrative databases can be subject to inaccuracies such as in the identification of health conditions (eg, RA) reflecting a documented diagnosis by a physician or an institution. The data elements from CIHI DAD used in this study for the purpose of defining the diagnosis of RA, however, have been found to be very reliable (CIHI Data Quality Study of the 2009-2010 Discharge Abstract Database, Ottawa: CIHI, 2012). The study excluded other commonly occurring immunological conditions; however, certain conditions including axial spondyloarthropathy, systemic lupus erythematosus and Sjogren's disease were not excluded and biologics could be prescribed for these indications even though not specifically indicated. The OHIP data set contains most physician billing claims paid by OHIP, including records by physicians that are not under a fee for service remuneration model. These records, referred to as shadow billing, are known to be incomplete since the physicians are salaried and the incentive to bill is reduced. This has an implication to the definition of RA, since every encounter with a physician may not be recorded in the OHIP data set. Since the ODB routinely captures claims for prescription drugs for people 65 years and older only, the study cohort is limited to that age group, which represents $44 \%$ of RA patients in Ontario as of 2010. ${ }^{10}$ Furthermore, ICES does not have data on prescriptions paid out of pocket or by private insurance companies, which could underestimate the use of biologic DMARDs and also makes distinguishing between biologic naïve and biologic experienced patients impossible. The RPDB provides basic demographic information about anyone who has ever received an Ontario health card number. Thus, the cohort of people diagnosed with RA is limited to those with health insurance coverage. Also, the ICES databases utilized did not directly capture marital status and educational level that can be considered a limitation of the study, since these aspects may reflect on adherence. However, patients' income levels were considered, and this could reflect the level of education of the patients included in the study. There was a larger number of non-adherent than adherent patient group at the earlier index date and the former had a longer duration of follow-up. This could be explained either by the possibility of better adherence over time or that patients with longer follow-up were more likely to become non-adherent as time goes by. To limit this potential for bias, sensitivity analyses were carried out using three separate cohorts capturing patients with 3 years, 5 years and 7 years of follow-up. There was no difference in the data between any of those cohorts and the whole cohort used in this study (data not shown). Finally, retrospective studies using a database can only explore the relationship between factors in that database and adherence. Potentially relevant factors that are not in this database will remain undiscovered and it is not possible to find a causal relationship. ${ }^{4}$

Finally, like most studies evaluating adherence, the definition of adherence is based on MPR, which is calculated based on filled claims and does not guarantee that patients have actually taken the medication. In addition, this study has inherent limitations of administrative database studies that include the lack of clinical outcome data for RA.

A central strength of this study is that it was conducted in a large diversified population cohort that included all RA patients aged 65 years and older treated with biologic DMARDs within the province of Ontario. Another strength is that the study is linked to many administrative databases, including health care resource utilization and drug use, allowing for a comprehensive analysis with the power to identify small effects with confidence along with minimization of potential biases. This study also included all biologic DMARDs (not limited to anti-TNFs), and future research can examine potential differences.

\section{Conclusion}

We found that adherence to biological DMARD therapy is associated with significantly lower health care resource utilization and the need for concomitant therapies such as NSAIDs/COXIBs and corticosteroids. These findings have implications on patients, physicians and health care payers and highlight the importance of adherence to therapy in the management of a chronic disease such as RA. 


\section{Acknowledgments}

This study made use of anonymized data from the ICES Data Repository, which is managed by the Institute for Clinical Evaluative Sciences with support from its funders and partners: Canada's Strategy for Patient-Oriented Research (SPOR), the Ontario SPOR Support Unit, the Canadian Institutes of Health Research and the Government of Ontario. The opinions, results and conclusions reported are those of the authors. No endorsement by ICES or any of its funders or partners is intended or should be inferred. Nonetheless, the authors wish to acknowledge the support of Refik Saskin and Nadia Gunraj for their help in the design and analysis of this study. Finally, we wish to thank Allen Lehman, Brendan Osborne, Cathy Tkaczyk and Karina Maslova for critical review of this manuscript. This study was funded by Janssen Inc. This paper was presented during 2016 as a poster presentation with interim findings at the following symposia: 21st International Society for Pharmacoeconomics and Outcomes Research (ISPOR) in Washington, DC (published in "Poster Abstracts" available online at https://www.ispor. org/research pdfs/52/pdffiles/PMS60.pdf and in Value in Health: http://dx.doi.org/10.1016/j.jval.2016.03.1091), and The European League Against Rheumatism (EULAR 2016) in London, UK (published in "Poster Presentations" in Epidemiology, health services and outcome research: http:// ard.bmj.com/content/75/Suppl 2/891.1).

\section{Disclosure}

The authors report no conflicts of interest in this work.

\section{References}

1. Singh JA, Saag KG, Bridges SL Jr, et al. 2015 American College of Rheumatology guideline for the treatment of rheumatoid arthritis. Arthritis Care Res. 2016;68(1):1-25.

2. Smolen JS, Landewe R, Breedveld FC, et al. EULAR recommendations for the management of rheumatoid arthritis with synthetic and biological disease-modifying antirheumatic drugs: 2013 update. Ann Rheum Dis. 2014;73(3):492-509.

3. Harrold LR, Andrade SE. Medication adherence of patients with selected rheumatic conditions: a systematic review of the literature. Semin Arthritis Rheum. 2009;38(5):396-402.

4. Pasma A, van't Spijker A, Hazes JM, Busschbach JJ, Luime JJ. Factors associated with adherence to pharmaceutical treatment for rheumatoid arthritis patients: a systematic review. Semin Arthritis Rheum. 2013; 43(1):18-28.

5. Curkendall S, Patel V, Gleeson M, Campbell RS, Zagari M, Dubois R. Compliance with biologic therapies for rheumatoid arthritis: do patient out-of-pocket payments matter? Arthritis Rheum. 2008;59(10): $1519-1526$.

6. Li P, Blum MA, Von Feldt J, Hennessy S, Doshi JA. Adherence, discontinuation, and switching of biologic therapies in medicaid enrollees with rheumatoid arthritis. Value Health. 2010;13(6):805-812.

7. Degli Esposti L, Sangiorgi D, Perrone V, et al. Adherence and resource use among patients treated with biologic drugs: findings from BEETLE study. Clinicoecon Outcomes Res. 2014;6:401-407.

8. Salt E, Frazier SK. Adherence to disease-modifying antirheumatic drugs in patients with rheumatoid arthritis: a narrative review of the literature. Orthop Nurs. 2010;29(4):260-275.

9. Park DC, Hertzog C, Leventhal H, et al. Medication adherence in rheumatoid arthritis patients: older is wiser. J Am Geriatr Soc. 1999;47(2): 172-183.

10. Widdifield J, Bernatsky S, Bombardier C, Paterson M. Rheumatoid arthritis surveillance in Ontario: monitoring the burden, quality of care and patient outcomes through linkage of administrative health data. Healthc Q. 2015;18(3):7-10.
Patient Preference and Adherence

\section{Publish your work in this journal}

Patient Preference and Adherence is an international, peer-reviewed, open access journal that focuses on the growing importance of patient preference and adherence throughout the therapeutic continuum. Patient satisfaction, acceptability, quality of life, compliance, persistence and their role in developing new therapeutic modalities and compounds to optimize

\section{Dovepress}

clinical outcomes for existing disease states are major areas of interest for the journal. This journal has been accepted for indexing on PubMed Central. The manuscript management system is completely online and includes a very quick and fair peer-review system, which is all easy to use. Visit http://www. dovepress.com/testimonials.php to read real quotes from published authors. 